\title{
REVIEW: Novel sources and functions of microbial lipases and their role in the infection mechanisms
}

\author{
Ananias Pascoal $^{\mathrm{a}, *}$, Letícia M. Estevinho ${ }^{\mathrm{a}}$, Ivone M. Martins ${ }^{\mathrm{a}, \mathrm{b}, 1}$, Altino B. Choupina ${ }^{\mathrm{a}}$ \\ ${ }^{a}$ CIMO-Mountain Research Center, Department of Biology and Biotechnology, Agricultural College of Bragança, Polytechnic Institute of Bragança, Campus Santa Apolónia, \\ E 5301-855, Bragança, Portugal \\ ${ }^{\mathrm{b}}$ CEB - Centre of Biological Engineering, University of Minho, 4710-057, Braga, Portugal
}

\section{A R T I C L E I N F O}

\section{Keywords:}

Lipases

Phytophthora cinnamomi

Biocatalysts

Biotechnological applications

\begin{abstract}
A B S T R A C T
Lipases belong to the family of serine hydrolases, which in turn include various esterase enzymes (E.C.3.1.1.1) They are involved in the cleavage of triacylglycerols to free fatty acids and glycerol in many important biological processes, as for instance routine metabolism of dietary triglycerides to cell signalling and inflammation. Lipases constitute a ubiquitous group of enzymes able to catalyse a number of different reactions, many of them of industrial interest. Particularly, microbial lipases exhibit a wide range of industrial applications, namely in pharmaceutical, food and detergents industry. The aim of this review is to summarize the recent achievements illustrating the importance and the versatility of microbial lipases, including their involvement in infection mechanisms.
\end{abstract}

\section{Introduction}

Lipases (triacylglycerol acyl hydrolases, E.C. 3.1.1.3) belong to the family of serine hydrolases, which include several esterase enzymes. These enzymes are able to catalyse the hydrolysis of fats and oils in the oil-water interface with the release of free fatty acids, diglycerides, monoglycerides, and glycerol $[1,2]$. Furthermore, they also have the ability to catalyse esterification reactions, transesterification and interesterification in organic solvents [3,4]. Lipases as catalysts have been reported to play a special and important role in the detergents industry, food production and processing, pharmaceutical, paper, cosmetics and chemical synthesis industries [2,5]. Several studies have been published reporting the different applications of lipases (Table 1). In fact, the use of lipases in the field of biotechnology has been known as a rentable business involving billions of dollars [6]. In the production of cosmetic products, they can function as active ingredients or as biocatalysts in the synthesis of specific cosmetic chemicals, mainly esters, aromatic compounds and active agents [7].

Lipases can split emulsified esters of glycerine and long-chain fatty acids such as triolein (trioleilglicerol, TC18) [8]. For esterases, the substrate is considered the standard tributyrin (tributirilglicerol, TC4), which in turn can be hydrolysed by lipases [9]. It is generally accepted that esterases can hydrolyse ester and triglyceride esters of short carbon chain $(<10$ carbons) bonds, releasing fatty acids of low molecular weight, and therefore are also called non-lipolytic esterases [6] or carboxylesterases [10], since lipases preferentially hydrolyse triglycerides of long chain ( $>10$ carbons) bonds.

Lipases are widely distributed in nature [3] being found in animals, such as pancreatic lipase, lipases of the tongue, milk, adipose tissue, etc.; in plants (mainly in oily seeds); in bacteria, mainly in species of the genera Chromobacterium, Pseudomonas and Staphylococcus; in yeasts, mainly in species of the genera Candida and Yarrowia lipolytica and in fungi especially in species of the genera Aspergillus, Geotrichum, Rhizopus, Mucor, Penicillium [3,11].

Lipases are quite diverse regarding their enzymatic properties and substrate specificity, which together with their easy availability makes them very attractive for multiple biological functions and biotechnological applications. Microbial lipases isolated from bacteria and fungi, are the most appealing in biotechnology and organic chemistry, mainly due to their properties, such as the shortest generation time, high yield of conversion of substrate into product, versatility and ease of mass production $[3,12]$.

\section{Kinetic and physicochemical characteristics}

Lipases are usually acidic glycoproteins [29], with a molecular mass between 20 and $60 \mathrm{kDa}$ and the isoelectric point may vary between 4 and 5 [30]. Most lipases have an optimal range of activity and stability

\footnotetext{
* Corresponding author.

E-mail address: ananias.pascoal@ipb.pt (A. Pascoal).

${ }^{1}$ Current affiliation.
} 
Table 1

Some fields of industrial applications of microbial lipases.

\begin{tabular}{|c|c|c|}
\hline Application field & Remarks & References \\
\hline Biotechnological & $\begin{array}{l}\text { - Catalyse a several reactions (transesterification and etherification), production of antidepressants, anti-hypertensive and } \\
\text { vasodilators; } \\
\text { - Generate enantiomerically enriched primary and secondary alcohols; } \\
\text { - Bioremediation; } \\
\text { - It is used for removing the triglyceride waxes industry, removing hydrophobic components that cause problems in paper } \\
\text { manufacture. }\end{array}$ & $\begin{array}{l}{[13,14]} \\
{[15]} \\
{[16,17]} \\
{[3,18,19]}\end{array}$ \\
\hline Food industry & $\begin{array}{l}\text { - Flavour enhancement in dairy products such as cheese butter and margarine; } \\
\text { - Brewing industry; } \\
\text { - Improve flavours of rice and alcoholic beverages; } \\
\text { - It is used in tea processing; } \\
\text { - Hydrolysis of milk fat; production of substitutes for butter and other additives used in cereals, snacks and chewing. }\end{array}$ & $\begin{array}{l}{[3,18-20]} \\
{[21]} \\
{[18]} \\
{[3,18]} \\
{[22]}\end{array}$ \\
\hline Detergent industry & $\begin{array}{l}\text { - Enhance the ability to remove tough stains; } \\
\text { - Industrial or household cleaners; dishwashing; } \\
\text { - Remove fat (lipids) stains. }\end{array}$ & $\begin{array}{l}{[5]} \\
{[3,18,23]} \\
{[3,18]}\end{array}$ \\
\hline Pharmaceutical and cosmetics & $\begin{array}{l}\text { - It is an important compound used in the synthesis of anti-inflammatory drugs (ibuprofen and Naxopreno); hair-waving } \\
\text { preparation; skin inflammations; slimming down out by fat removal; } \\
\text { - Stereo-selectivity } \\
\text { 2-phenyl-propanoic acid, important compound used in the synthesis of anti-inflammatory drugs, it can be obtained by } \\
\text { transesterification reactions. }\end{array}$ & $\begin{array}{l}{[20,24,25]} \\
{[26]} \\
{[20,24,25]}\end{array}$ \\
\hline Medical applications & $\begin{array}{l}\text { - It is used as digestive aids; treatment of malignant tumours; treatment of gastrointestinal disturbances, dyspepsia, cutaneous } \\
\text { manifestations of digestive allergies. }\end{array}$ & [3] \\
\hline Other applications & $\begin{array}{l}\text { - Leather manufacture (Degreasing of leather); } \\
\text { - It is used to improve the recovery of humidity and facilitates to the removal or dissolving fatty stains in textile industry; } \\
\text { - Has an enormous advantage in oleo-chemical industry because it saves energy and minimizes thermal degradation during the } \\
\text { reactions of hydrolysis, glycerolysis, and alcoholysis } \\
\text { - In the biodiesel production catalysed by lipases through transesterification of triglycerides with short-chain alcohols. In this } \\
\text { process, different types of oils, such as soybean, sunflower, corn, jatropha, karanja, waste cocking oil, Chlorella protothecoides, } \\
\text { Chlorella protothecoides, animal fat, groundnut, canola, coconut and palm oil has been used; } \\
\text { - Fine and bulk chemical industries (acrylamide, wastewater treatment, papermaking, pesticide formulation, soil erosion } \\
\text { prevention and gel electrophoresis); } \\
\text { - For the resolution of Racemic Acids and Alcohols; } \\
\text { - In the Enantioselective catalysis; } \\
\text { - Biosensors; } \\
\text { grease is ised in waste treatment (degradation of organic debris and sewage treatment, cleaning of holding tanks, septic tanks, }\end{array}$ & $\begin{array}{l}{[3,18,19]} \\
{[3,18,20,21]} \\
{[23,27]} \\
{[23,27]} \\
{[23,27]} \\
{[28]} \\
{[20]} \\
{[1,19]} \\
{[3,18]}\end{array}$ \\
\hline
\end{tabular}

for $\mathrm{pH}$ values between 6.0 and 8.0 and temperature between 30 and $40{ }^{\circ} \mathrm{C}$. However, these properties may vary significantly depending on the source, or even between isoforms produced by one microorganism.

Lipases are water soluble enzymes that act on the metabolism and digestion of triacylglycerols [31,32], thus, the reactions catalysed by lipases occur using a lipidic substrate in the form of emulsion. However, they have a better performance when the substrate concentration is sufficiently high to form micellar aggregates or emulsions, as they can interact with the user interface of the aggregate substrate [31]. This increased activity in the presence of micelles or emulsions is due to the phenomenon known as interfacial activation [33], which in lipases has been early observed in studies undertaken with pancreatic lipases of pig [34,35]. The purified lipases allowed the study of the phenomenon in detail, where the lipase activity of triacetin increased remarkably, since it exceeded its limit of solubility.

The model of the pancreatic lipase enzyme was proposed with the assumption that the interfacial activation could answer a conformational change suffered by lipases [36]. These reactions cannot be described by a Michaelis-Menten reaction, since the hydrolysis process has several steps [36]. With respect to the model substrate, the activation is explained with changes in the lipid substrate interface: increasing the local concentration of the substrate instead of the active site, will reduce the orientation and conformation of lipids in the interface states related to the geometry of the active site of the enzyme, or lessen the degree of hydration of the substrate [37,38].

\section{Structural characteristics}

Pleiss and co-workers, have compared the structure of the active site of various esterases and lipases and they observed that those from lipases are normally wider and deeper than the ones from esterases, which could explain the ability of lipases to recognize a more varied and longer chains substrates (e.g. triolein) [38,39].

When a lipase in the aqueous phase is under its solubility limit or in the absence of/or at low concentration emulsion of a lipid substrate, exists typically a helix covering the active site, in particular, an oligopeptide helix motif termed "lid" which protects the active site. This amphiphilic cover consists of polar amino acids on the outside and nonpolar amino acids on the inner side, in contact with the active site [39]. It has been reported that lipases with the lid covering the active site are in a closed conformation and, in the presence of an emulsion (upon contact with the interface formed by the lipid lipases), undergo a conformational change in the lid region exposing their active site for the hydrolysis of triacylglycerol molecules [40]. The active site is only exposed when the cover opens, i.e. the enzyme only catalyses a reaction in hydrophobic-hydrophilic interfaces or in the presence of a hydrophobic solvent. The mechanism of conformational change form "closed to open" is called interfacial activation [26].

The active site of lipases is generally characterized by a triad of serine, histidine and an acid residue (aspartic or glutamic acid) classified as serine hydrolases, which are essential for all the reactions catalysed by these enzymes [6,41]. The mechanisms involved in the catalysis of serine hydrolases has been previously proposed [41,42]. The first step consists of the removal of a proton from serine, mechanism by which aspartate and histidine residues are required. The hydroxyl group of serine attacks the carbonyl carbon forming an intermediate substrate. The presence of an oxoanionic spacer contributes to the stabilization of the charge distribution and also to reduce the minimum energy for the formation of a tetrahedral intermediate. The last step is the deacylation: the acyl group is transferred to the enzyme and released by the attack of a nucleophile (e.g. $\mathrm{H}_{2} \mathrm{O}$ ), thus the catalytic centre of the enzyme is regenerated. 


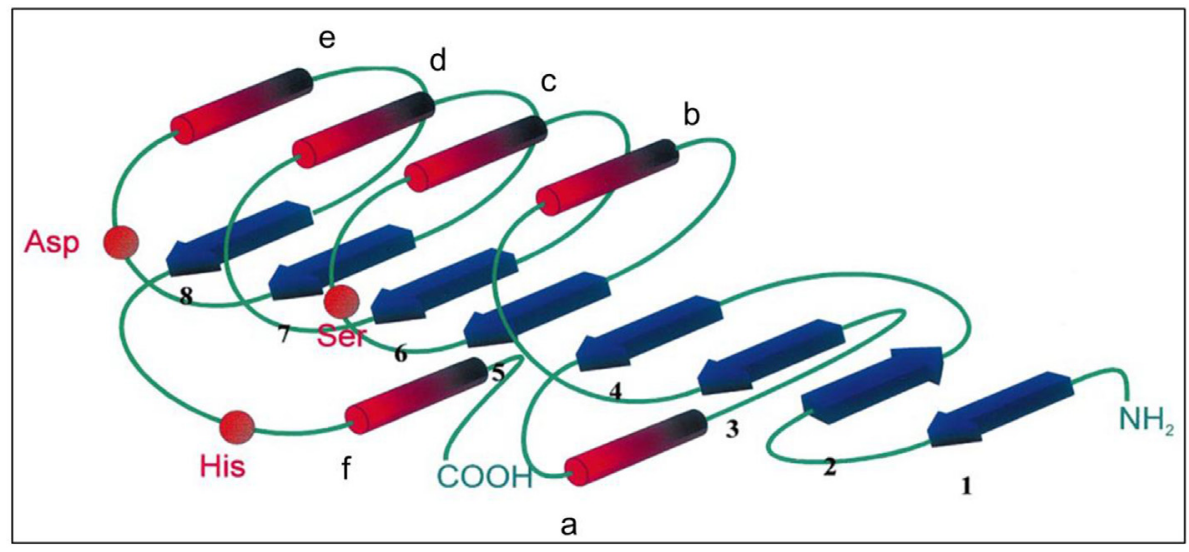

Fig. 1. Schematic representation of the structural motif conserved enzyme family of $\alpha / \beta$ hydrolase. The filaments forming the structure in $\beta$-pleated sheet (1-8) are indicated by blue arrows and the structures in $\alpha$-helices (A to F) are indicated by red columns. The relative positions of the amino acids of the catalytic triad are indicated by red beads. The aminoterminal region is indicated by $\mathrm{NH}_{2}$ at the beginning of the chain, and by $\mathrm{COOH}$ for the carboxy-terminal region for the end of the chain. The figure was reprinted with permission, from Ref. [29]. (For interpretation of the references to colour in this figure legend, the reader is referred to the Web version of this article.)
The serine residue involved in the catalytic triad typically is a pentapeptide with a conserved consensus sequence (Ser-Gly-X-Gly-X), where X represents any of 20 amino acids. Currently, some databases of conserved domains, for example the PROSITE $[43,44]$ and the Pfam [44] use the sequence of pentapeptide and the region around it to classify a given amino acid sequence encoding a lipase or esterase.

It was observed that all tertiary structures solved with lipases possess the $\alpha / \beta$ hydrolase configuration [45] (Fig. 1), which has been identified in 1992 by comparing five enzymes with completely different catalytic functions: dienolactona hydrolase, haloalkane dehalogenase, serine carboxypeptidase II, wheat acetylcholinesterase and Geotrichum candidum lipase. These enzymes have no similarity between sequences, do not act on similar substrates, and do not have the same nucleophile donor. However, they have structural similarities, combined with the preservation of the arrangement of the catalytic residues [46]. According to these authors, the number of groups of enzymes with $\alpha / \beta$ hydrolase configuration has increased, making this one of the most versatile and widely distributed configuration type of proteins.

Besides having the same reaction mechanism, the carboxylesterases and lipases have some structural similarities. The main one is the presence of the $\alpha / \beta$ hydrolase configuration, consisting of several $\alpha$-helices and $\beta$-sheets interspersed. This is a fairly common configuration hydrolases, found also in other families of enzymes such as epoxide hydrolases (EC 3.3.2.3) [47] and haloperoxidases (EC 1.11.1.) [48].

\section{Lipases role in pathogenicity mechanisms}

Pathogenicity has been defined as the ability of a pathogen to infect [49], being their pathogenicity expressed by means of their virulence [50].

The lipase 8 (LIP8) gene plays an importance role in the virulence of Candida albicans. These researchers observed that Reducing LIP8 expression found in reduced growth in lipid-containing media and the deficit of mutants in LIP8 gene were significantly less virulent in a murine intravenous infection model [51]. Also, Feng [52] and Silva [53], reported that Lip5 and Lip8 from C. albicans promote host pathogen interaction. Moreover, extracellular phospholipase and proteases enzymes have been pointed as a virulence factor in the pathogenesis of haematogenous infections caused by $C$. albicans, altering their surface characteristics as adherence and penetration [54], Other studies revealed that some pathogenic microorganisms can grow in the host by using haemoglobin as their source of iron. Candida species can produce haemolysins that degrade haemoglobin and extract elemental iron from host cells. Haemolysins have been appointed to be the key of virulence factors because they might promote the survival and persistence of the pathogen in the host [55].

Candida albicans is known as an opportunistic pathogen involved in oral, vaginal, and systemic infections and responsible for a high mortality rate in the United States due to their infection in the bloodstream
[56]. This pathogen has been pointed as the most prevalent human fungal pathogen, with an ability to inhabit diverse host niches and cause disease in both immunocompetent and immunocompromised patients $[57,58]$.

Candida albicans, in order to exercise its function of infection in the host niches, needs a wide range of virulence factors and fitness attributes [59]. Some of those factors like morphological transition between yeast and hyphal forms, adhesins and invasins, thigmotropism, the formation of biofilms, phenotypic switching, surface hydrophobicity, have been pointed as affecting the $C$. albicans virulence $[51,53,60]$. Also fitness attributes as rapid adaptation to fluctuations in environmental $\mathrm{pH}$, metabolic flexibility, powerful nutrient acquisition systems and robust stress response machineries have been pointed as virulence factors [59]. Given that, the secretion of aspartic proteinases by C. albicans has been reported as the key of their virulence [61-63]. Regarding biofilms production, lipases have a role in helping the pathogen to evade host immune response and the mechanisms of their virulence has been clearly described [64]. According to these researchers, the first step was characterized by the adhesion and colonization of the yeast to the host cell surfaces by the expression of adhesins. Followed by thigmotropism, invasion of host cell through induced endocytosis, biofilm formation, evasion from the host immune response, inflammatory response and finally the host infection; among other factors that influence fungal pathogenicity as i) robust stress response mediated by heat shock proteins, ii) auto-induction of hypha formation iii) excretion of ammonia and concomitant extracellular alkalinisation, etc. Other studies revealed that $C$. albicans can use two mechanisms to invade host cells as induced endocytosis and active penetration $[13,65,66]$. During the induced endocytosis, the fungus expresses specialized proteins on the cell surface that mediate binding to host ligands thereby triggering the engulfment of the fungal cell into the host cell [14]. The lipases Lip5, Lip6, Lip8 and Lip9 have been reported [67] as some of the secreted by C. albicans which enable the organism to adhere and colonize during infection in humans.

Also in mechanisms of infection in plants by fungi, in particular of the genus Phytophthora ssp. several authors report the participation of lipases in several steps of these mechanisms [68-73].

One such plant pathogen, Phytophthora cinnamomi belongs to the class of Oomycetes, that includes several of the most devastating omnivore pathogens for the natural ecosystems worldwide [52,73,74]. Phytophthora cinnamomi is a destructive and widespread soil-borne pathogen which infects woody plant hosts and, in the northeast of Portugal and in the Spanish region, has been reported to affect mainly chestnut-tree (Castanea sativa), cherry-tree (Prunus avium) and cork oak (Quercus suber), [73,75-77]. In fact, P. cinnamomi, due to its capacity to destroy natural plant communities and causing diseases with and economically important impact in forestry, horticulture, and in the nursery industry, it's called by some authors as "biological bulldozer" [78].

The infection mechanism of this pathogen has been characterized by 
our group in previous studies [75]. Some proteins as endo-1,3-betaglucanase, endo-glucanase, glucanase inhibitor protein (GIP), necrosisinducing Phytophthora protein 1 (NPP1) and transglutaminase have been pointed to be involved in the mechanisms of infection of this pathogen [79-81]. Pathogenicity of many biotrophic and hemi-biotrophic pathogens has been clearly described [82]. According to these researchers the biotrophic fungi and Oomycetes produce virulence proteins that are recognized and are pathogenic for plants. Their infection process is related to the formation of haustoria within living plant cells. The pathogen penetrates the cell wall and invaginates the plasma membrane during infection, where it forms this specialized feeding structure. Therefore, the haustorium appears to play an essential role in nutrient acquisition and may be involved in the redirection of host metabolism and the suppression of host defences. Among the biotrophic fungi, Melampsora lini has yielded the most information regarding the virulence proteins [83] and four proteins (AvrL567, AvrM, AvrP123 and AvrP4) involved in virulence have been reported [84].

In the available nucleotide databases we can find two genomes of P. cinnamomi $[85,86]$. The study of these sequences, their structure functions and interactions will allow elucidating the genetic and molecular mechanisms, defence and attack strategies of the fungus $P$. cinnamomi in order to establish more efficient and resilient control strategies.

In the nucleotide databases http://www.ebi.ac.uk/ena and https:// www.ncbi.nlm.nih.gov/, there are two genome assembly contig set [85] and one transcriptome assembly contig set, from $P$. cinnamomi [86].

The analysis of these sequences has allowed us to identify several ORF's that encode proteins with relevant role in the virulence of $P$. cinnamomi. We have also identified two ORF's that codify proteins with esterase/lipase's domains with similarity to lipases described in other Phytophthora species involved in pathogenicity mechanisms. These sequences are in the database "fungidb", with the references PHYCI_76143 and PHYCI_89229 and encode proteins with 309 and 425 amino acids respectively. The primary sequence of these lipases and their alignment by the Clustal algorithm with other lipases of the genus Phytophthora is shown in Fig. 2. In addition to the similarity between Phytophthora lipases, we can also observe in the figure the common serine residue involved in the catalytic triad with a conserved consensus sequence (Ser-Gly-X-Gly-X), where X represents any of 20 amino acids.

The structural prediction of these $P$. cinnamomi lipases was performed on the Phyre2 server [88], based on the homology of these lipases with the crystallized dog's (Canis lupus familiaris) gastric lipase, with access code 1K8Q in Protein Data Bank [89] (Fig. 3).

The extracellular lipases of some pathogens as Staphylococcus aureus, Staphylococcus epidermidis, Propionibacterium acnes and Pseudomonas aeruginosa, as well as pathogenic fungi, such as Malassezia furfur and Hortaea werneckii, have been proposed as potential virulence factors [51].

\section{Biotechnological applications of lipases}

Lipases are produced by plants, animals and microbes but only microbial lipases are found to be industrially important with an enormous biotechnological potential, due to the diverse enzymatic properties, substrate specificity, chemoselectivity, regioselectivity and stereoselectivity $[9,90]$. Even though plant lipases are also available, they are not commercially exploited because of the low yield and the complexity of the processes involved. Regarding the lipases from animal origin, some disadvantages have been reported, among which: the presence of bitter tasting amino acids, the presence of residual animal hormones or viruses and the undesirable effects in the processing of vegetarian diets [11].

Current discoveries about fungal lipases associated with pathogenicity have given these enzymes great versatility with multiple functions and applications.
Esterases and lipases are capable of catalysing a series of reactions, possessing good stability in organic solvents. For that reason, they can be considered excellent biocatalysts in intermediate stages of conventional chemical processes, and in catalysis of chemical reactions involving substrates insoluble in aqueous media. Moreover, they are used in the resolution of racemic mixtures and in the selective removal of certain compounds.

Concerning the microbial lipases, these exhibit a wide range of industrial applications, because of the higher stability, high yield of conversion of substrate into product, the great versatility to adapt to environmental conditions and the simplicity in genetic manipulation and growth conditions [11,90]. A high synthesis rate is obtained with simple processes and low investment and, hence these enzymes are mostly extracellular, their extraction, isolation and purification is simple [91].

The biotechnological potential of lipases is related with their ability to catalyse various reactions. Typically, they preserve the structure and are stable in organic solvents, not requiring the presence of cofactors but requiring stable conditions of temperature and $\mathrm{pH}$. In addition, these enzymes exhibit a broad substrate specificity and high enantioselectivity [24,91-94].

Nowadays, lipases are used for the generation of enantiomerically enriched primary and secondary alcohols and, to a lesser extent, to obtaining chiral carboxylic acids and secondary amines [15]. The stereoselectivity of lipases is useful in the synthesis of biopolymers such as, for example, polyesters and polyphenols in the kinetic resolution of racemic mixtures in the secondary hydrolysis reactions, the transesterification and alcohol etherification [16,25].

The panorama of lipases use encompasses many industries: enzymes of microbial origin are used in food industry, in the manufacture of detergents (hydrolysis of fats), cosmetics (removal of lipids) and wastewater treatment (decomposition and removal of oily substances). As these enzymes have enormous catalytic potential, they are also used as ideal biocatalysts in organic chemistry, fine chemicals (synthetic esters) in the pharmaceutical industry, and in the production of food additives (flavour enhancement) [11,91,93].

\subsection{Pharmaceutical industry}

The synthesis of bioactive substances has been practiced over the years by means of conventional organic chemistry. This synthesis route, in some cases, can result in problems such as instability of the molecule on the reaction conditions and the formation of racemic mixture [26]. The ability of lipases to resolve racemic mixtures by the synthesis of a single enantiomer is currently exploited for drug production by the pharmaceutical industry.

Microbial lipases are used to concentrate polyunsaturated fatty acids from animal and botanical lipids, and their mono and diacylglycerides are used to produce a variety of pharmaceuticals. The use of lipases in pharmaceutical industry is due, in particular, to the enantioselectivity exhibited by many of these enzymes. The enantioselective catalysis allows the obtention of optically pure products, since these enzymes are chiral molecules capable of recognizing and acting preferably in the isomers of a racemic mixture. This feature is extremely advantageous because, in many cases, the isomers (R and S) have a biological activity, while others are less active or even toxic [20].

One important compound used in the synthesis of non-steroids antiinflammatory drugs (Ibuprofen and Naxopreno) is 2-phenyl-propanoic acid, which can be obtained by transesterification reactions or hydrolysis of the corresponding ester catalysed by lipases [19]. Another example is the use of a Candida antarctica lipase resolution of racemic thiotetronic acid derivatives to obtain the compound (R)-thiolactomycin which has a chiral quaternary carbon atom C5 [15,19,95].

Lipases are also used in the production of antidepressants, anti-hypertensives and vasodilators [18]. 


\begin{tabular}{|c|c|}
\hline $\begin{array}{l}\text { PHYCI_110663 } \\
\text { PITG_01274 } \\
\text { PHYCI_89229 } \\
\text { PSURA_76385 }\end{array}$ & 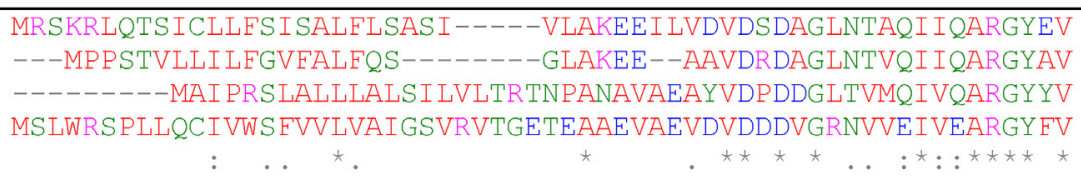 \\
\hline $\begin{array}{l}\text { PHYCI_110663 } \\
\text { PITG_01274 } \\
\text { PHYCI_89229 } \\
\text { PSURA_76385 }\end{array}$ & 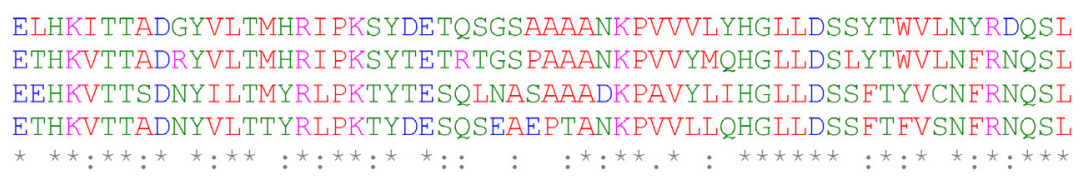 \\
\hline $\begin{array}{l}\text { PHYCI_110663 } \\
\text { PITG_01274 } \\
\text { PHYCI_89229 } \\
\text { PSURA_76385 }\end{array}$ & 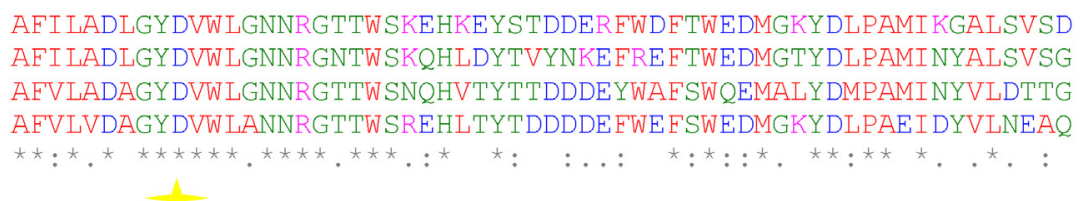 \\
\hline $\begin{array}{l}\text { PHYCI_110663 } \\
\text { PITG_01274 } \\
\text { PHYCI_89229 } \\
\text { PSURA_76385 }\end{array}$ &  \\
\hline $\begin{array}{l}\text { PHYCI_110663 } \\
\text { PITG_01274 } \\
\text { PHYCI_89229 } \\
\text { PSURA_76385 }\end{array}$ & 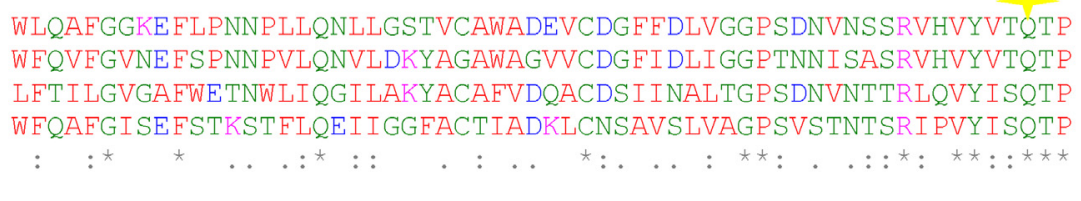 \\
\hline $\begin{array}{l}\text { PHYCI_110663 } \\
\text { PITG_01274 } \\
\text { PHYCI_89229 } \\
\text { PSURA_76385 }\end{array}$ & 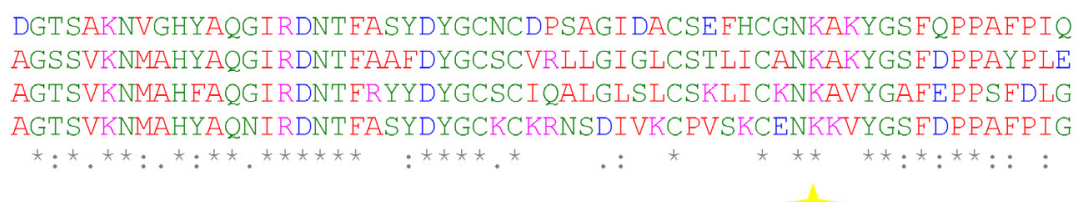 \\
\hline $\begin{array}{l}\text { PHYCI_110663 } \\
\text { PITG_01274 } \\
\text { PHYCI_89229 } \\
\text { PSURA_76385 }\end{array}$ & 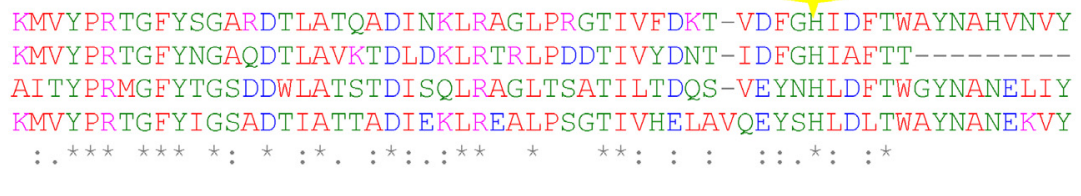 \\
\hline $\begin{array}{l}\text { PHYCI_110663 } \\
\text { PITG_01274 } \\
\text { PHYCI_89229 } \\
\text { PSURA_76385 }\end{array}$ & 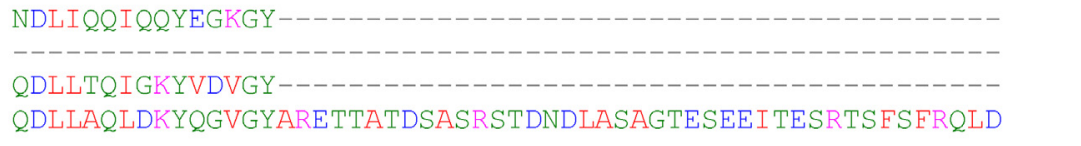 \\
\hline
\end{tabular}

Fig. 2. Alignment of the primary structures of $P$. cinnamomi (PHYCI_110663 and PHYCI_89229), P. infestans (PITG_01274), and P. ramorum (PSURA_76385) lipases (FungiDB). The rectangle delimits a conserved consensus sequence (Ser-Gly-X-Gly-X) the serine residue involved in the catalytic triad and under the yellow star the active site of a lipase contains a catalytic triad consisting of Ser - His - Glu. The software Clustal Omega multiple sequence alignment program, was used [87]. (For interpretation of the references to colour in this figure legend, the reader is referred to the Web version of this article.)

\subsection{Food industry}

These enzymes have been extensively used in the food industry, especially in the dairy industry for the hydrolysis of milk fat, the modification of the fatty acid chain lengths to enhance the cheese characteristics and, more recently, to accelerate cheese ripening and the lipolysis of butter fat and cream. In addition, lipases have been used in selective hydrolysis of fat, allowing its use in the formation of flavoured products, in the production of substitutes for butter and other additives used in cereals, snacks and chewing. The addition of these hydrolysates provides a variety of food sensory characteristics [96]. Lipases are also used to modify the taste of food, the synthesis of esters of fatty acids, and short chain alcohols, these being the basic flavour and aroma compounds [20].

Another example can be given in the baking industry, in the manufacture of bread lipase degrade lipids from wheat changing its interaction with the gluten, obtaining a dough conditioner result in increasing bread volume and improved texture. Hydrolysis performed by specific lipases is applied to obtain monoacylglycerol which are used as emulsifying agents [97].

\subsection{Detergent industry}

The use of enzymes in detergent formulations is common in developed countries, with over half of all detergents presently available containing enzymes. Lipases are used in the detergent industry to facilitate the breaking of bonds present in the triglycerides and hence solubilise grease adhered to the fabric, therefore enhancing the ability to remove tough stains. These enzymes make the detergent environmentally safe, by reducing the environmental load, as they save energy by enabling a lower wash temperature. Also, the products are mostly biodegradable and leave no harmful residues [5]. 
a

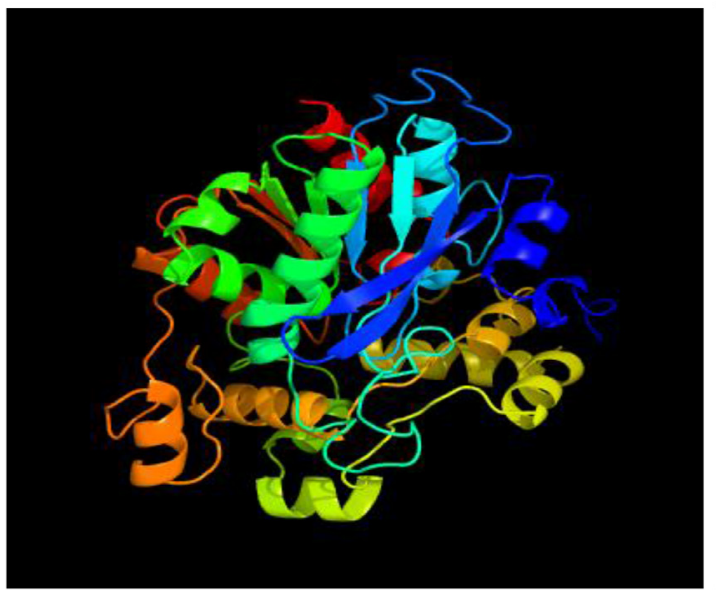

b

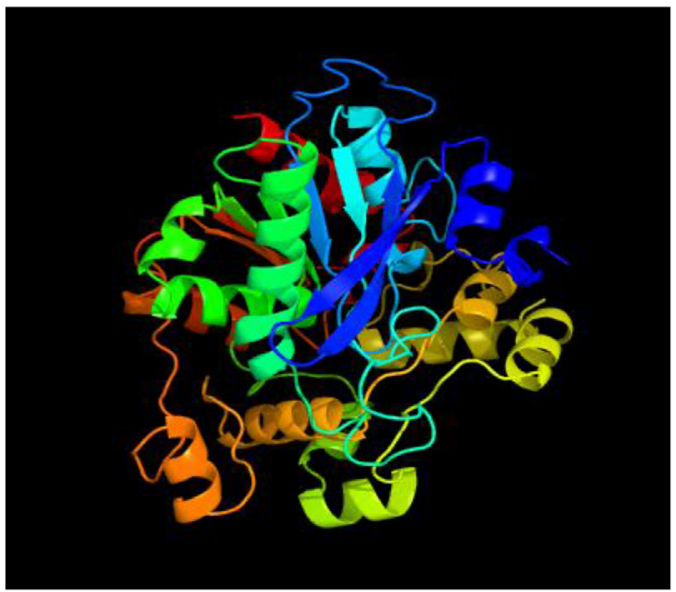

Fig. 3. 3-D structure prediction of $P$. cinnamomi lipases, based on template model dog gastric lipase (1K8Q in PDB) with 371 residues for PHYCI_110663 (left figure a) and 367 residues for PHYCI 89229 (right figure b) and $86 \%$ modelled with $100.0 \%$ confidence by the single highest scoring template. The structural predictions were performed through the Phyre2 server (http://www.sbg.bio.ic.ac.uk/phyre2/html/page.cgi?id=index) and the structural representation was performed by Pymol program, who's the version can be installed in https://pymol.org/2/.

Examples of enzymes used in detergents are Lipolase (Novozymes) obtained from the fungus Thermomyces lanuginosa and expressed in Aspergillus oryzae; the Lumafast ${ }^{\circ}$ (Genencor, USA) and Lipomax (GistBrocades, The Netherlands), bacterial lipases from Pseudomonas mendocina, and Pseudomonas alcaligenes [27].

The most important commercial application area for hydrolytic lipases is industrial or household cleaners [23], which is generally used in combination with one or more enzymes such as proteases, amylases and cellulases, responsible for the removal of various fats [18].

\section{Final remarks}

The recent DNA sequencing techniques with platforms that allow massive sequencing, combined with advanced bioinformatics capabilities allow us to deduce the role of many molecular factors in metabolic pathways. It is possible that many molecules have roles in metabolic pathways that until our days are unknown. The recent associations of lipases in the pathogenicity mechanisms of some microorganisms confirms the high versatility of these enzymes. However, much is unknown about the concrete action of these enzymes in the metabolic pathways involved in pathogenicity mechanisms. We think that the silencing of lipase genes in phytopathogenic fungi and subsequent plant infection with these fungi may help to better understand the role of these enzymes in the infection.

The discovery of molecule factors and their interactions in the metabolic pathways of infection is an important step in the development of prevention strategies, therapy processes and control of fungal infections in plants.

\section{Conflicts of interest}

The authors declare that there are no conflicts of interest. Also, are indebted to the careful and constructive criticisms of the reviewers.

\section{Acknowledgments}

A. Pascoal would like to thank Foundation for Science and Technology (FCT, Portugal), Programa Operacional Pontencial Humano (POPH) and European Union (EU) for his Postdoctoral grant SFRH/ BPD/91380/2012. The authors also are grateful to the Centre of Molecular and Environmental Biology, funded by FCT, UID/BIA/ 04050/2013 (POCI-01-0145-FEDER-007569) and by the European Regional Development Fund (ERDF) through the COMPETE2020 -
Programa Operacional Competitividade e Internacionalização (POCI).

\section{References}

[1] S.C. Gopinath, P. Anbu, T. Lakshmipriya, A. Hilda, Strategies to characterize fungal lipases for applications in medicine and dairy industry, BioMed Res. Int. 2013 (2013) 154549

[2] A. Guldhe, B. Singh, T. Mutanda, K. Perrnaul, F. Bux, Advances in synthesis of biodiesel via enzyme catalysis: novel and sustainable approaches, Renew. Sustain. Energy Rev. 41 (2015) 1447-1464.

[3] A.K. Singh, M. Mukhopadhyay, Overview of fungal lipase: a review, Appl. Biochem. Biotechnol. 166 (2) (2012) 486-520.

[4] P. Villeneuve, J.M. Muderhwa, J. Graille, M. Haas, Customizing lipases for biocatalysis: a survey of chemical, physical and molecular biological approaches, J. Mol Catal. B Enzym. 9 (2000) 113-148.

[5] K.E. Jaeger, M.T. Reetz, Microbial lipases form versatile tools for biotechnology, Trends Biotechnol. 16 (1998) 396-403.

[6] K.E. Jaeger, B.W. Dijkstra, M.T. Reetz, Bacterial biocatalysts: molecular biology, three-dimensional structures, and biotechnological applications of lipases, Annu. Rev. Microbiol. 53 (1999) 315-351.

[7] M.B. Ansorge-Schumacher, O. Thum, Immobilised lipases in the cosmetics industry, Chem. Soc. Rev. 42 (2013) 6475-6490.

[8] A.R. Macrae, R.C. Hammond, Present and future applications of lipase, Biotech Engin Rev 3 (1985) 193-217.

[9] R. Sharma, Y. Chisti, U.C. Banerjee, Production, purification, characterization, and applications of lipases, Biotechnol. Adv. 19 (2001) 627-662.

[10] E.S. Lin, S.C. Sung, Cultivating conditions influence exopolysaccharide production by the edible Basidiomycete Antrodia cinnamomea in submerged culture, Int. J. Food Microbiol. 108 (2006) 182-187.

[11] P. Ellaiah, T. Parabhakar, B. Ramakrishna, A.T. Taleb, K. Adinarayana, Production of lipase by immobilized cells of Aspergillus niger, Process Biochem. 39 (2004) 525-528.

[12] H. Chahinian, Y.B. Ali, A. Abousalham, S. Petry, L. Mandrich, G. Manco, S. Canaan, L. Sarda, Substrate specificity and kinetic properties of enzymes belonging to the hormone-sensitive lipase family: comparison with non-lipolytic and lipolytic carboxylesterases, Biochim. Biophys. Acta 1738 (2005) 29-36.

[13] W. Zhu, S.G. Filler, Interactions of Candida albicans with epithelial cells, Cell Microbiol. 12 (3) (2010) 273-282.

[14] Q.T. Phan, C.L. Myers, Y. Fu, D.C. Sheppard, M.R. Yeaman, W.H. Welch, A.S. Ibrahim, J.E. Edwards Jr., S.G. Filler, Als3 is a Candida albicans invasin that binds to cadherins and induces endocytosis by host cells, PLoS Biol. 5 (3) (2007) e64.

[15] D. Isaksson, K. Sjodin, H.E. Hogberg, Enantiomerically enriched cryptone by lipase catalysed kinetic resolution, Tetrahedron: Asymmetry 17 (2006) 275-280.

[16] K.E. Jaeger, T. Eggert, Lipases for biotechnology, Curr. Opin. Biotechnol. 13 (2002) 390-397.

[17] A. Kumar, S.S. Kanwar, Catalytic potential of a nitrocellulose membrane-immobilized lipase in aqueous and organic media, J. Appl. Polym. Sci. 1 (2012) E37-E44.

[18] F. Hasan, A.A. Shah, A. Hameed, Industrial application of microbial lipase, Enzym. Microb. Technol. 39 (2006) 235-251.

[19] A. Pandey, S. Benjamin, C.R. Soccol, P. Nigam, N. Krieger, V.T. Soccol, The realm of microbial lipases in biotechnology, Biotechnol. Appl. Biochem. 29 (Pt 2) (1999) 119-131.

[20] M. Arand, A. Cronin, M. Adamska, F. Oesch, Epoxide hydrolases: structure, 
function, mechanism, and assay, Methods Enzymol. 400 (2005) 569-588.

[21] I. Es, J.D.G. Vieira, A.C. Amaral, Principles, techniques, and applications of biocatalyst immobilization for industrial application, Appl. Microbiol. Biotechnol. 99 (2015) 2065-2082.

[22] M. Virto, C. F, M.A. Bustamante, L.J. Barron, M. Aramburu, M.S. Vicente, F.J. PérezElortondo, M. Albisiu, M. De Renobales, Lamb rennet paste in ovine cheese manufacture, Int. Dairy J. 13 (2003) 391-399.

[23] K.T. Lee, T.A. Foglia, K.S. Chang, Production of alkyl ester as biodiesel from frac tionated lard and restaurant grease, J. Am. Oil Chem. Soc. 79 (2002) 191-195.

[24] E. Rigo, J.L. Ninow, M. Di Luccio, V. Oliveira, E. Polloni, D. Remonatto, F. Arbter, R. Vardanega, D. Oliveira, H. Treichel, Lipase production by solid fermentation of soybean meal with different supplements, LWT - Food Sci. Technol. (LebensmittelWissenschaft -Technol.) 43 (2010) 1132-1137.

[25] [2T. Schulz, J. Pleiss, R.D. Schmid, Stereoselectivity of Pseudomonas cepacia lipase toward secondary alcohols: a quantitative model, Protein Sci. 9 (2000) 1053-1062.

[26] A.M. Brzozowski, H. Savage, C.S. Verma, J.P. Turkenburg, D.M. Lawson, A. Svendsen, S. Patkar, Structural origins of the interfacial activation in Thermomyces (Humicola) lanuginosa lipase, Biochemistry 39 (2000) 15071-15082.

[27] H. Horchani, H. Mosbah, N.B. Salem, Y. Gargouri, A. Sayari, Biochemical and molecular characterisation of a thermoactive, alkaline and detergent-stable lipase from a newly isolated Staphylococcus aureus strain, J. Mol. Catal. B Enzym. 56 (2009) 237-245.

[28] S. Abraham, N.R. Kamini, M.K. Gowthaman, Process strategies for alkaline lipase production using Aspergillus Niger MTCC, 2594, Int. J. Appl. Pharm. 1 (2011) 126-133.

[29] U.T. Bornscheuer, Microbial carboxyl esterases: classification, properties and application in biocatalysis, FEMS Microbiol. Rev. 26 (1) (2002) 73-81.

[30] A. Hiol, M.D. Jonzo, D. Druet, L. Comeau, Production, purification and character ization of an extracellular lipase from Mucor hiemalis f. hiemalis, Enzym. Microb. Technol. 25 (1-2) (1999) 80-87.

[31] A. Aloulou, J.A. Rodriguez, S. Fernandez, D. van Oosterhout, D. Puccinelli, F. Carriere, Exploring the specific features of interfacial enzymology based on lipase studies, Biochim. Biophys. Acta 1761 (2006) 995-1013.

[32] A. Svendsen, Lipase protein engineering, Biochim. Biophys. Acta 1543 (2000) 223-238.

[33] L. Sarda, P. Desnuelle, Actions of pancreatic lipase on esters in emulsions, Biochim. Biophys. Acta 30 (1958) 513-521.

[34] K. Holwerda, P.E. Verkade, A.H.A. de Willigen, Vergleichende Untersuchungen über die Verseifungsgeschwindigkeit einiger Einsäuriger Triglyceride unter Einfluss von Pankreasextrakt. I. Der Einfluss des Verteilungszustandes der Triglyceride auf die Verseifungsgeschwindigkeit, Recl Trav Chim Pay B 55 (1936) 43-57.

[35] F. Schonheyder, K. Volqvartz, On affinity of pig pancreas lipase for tricaproin in heterogeneous solution, Acta Physiol. Scand. 9 (1945) 57-67.

[36] P. Desnuelle, L. Sarda, G. Ailhaud, Inhibition of pancreatic lipase by diethyl-p-nitrophenyl phosphate in emulation, Biochim. Biophys. Acta 37 (1960) 570-571.

[37] J.M. Muderhwa, H.L. Brockman, Lateral lipid distribution is a major regulator of lipase activity. Implications for lipid-mediated signal transduction, J. Biol. Chem. 267 (1992) 24184-24192.

[38] J.M. Smaby, J.M. Muderhwa, H.L. Brockman, Is lateral phase separation required for fatty acid to stimulate lipases in a phosphatidylcholine interface? Biochemistry 33 (1994) 1915-1922.

[39] J. Pleiss, M. Fischer, R.D. Schmid, Anatomy of lipase binding sites: the scissile fatty acid binding site, Chem. Phys. Lipids 93 (1998) 67-80.

[40] N. Kamiya, H. Kasagi, M. Inoue, K. Kusunoki, M. Goto, Enantioselective recognition mechanism of secondary alcohol by surfactant-coated lipases in nonaqueous media, Biotechnol. Bioeng. 65 (1999) 227-232.

[41] M.T. Reetz, Lipases as practical biocatalysts, Curr. Opin. Chem. Biol. 6 (2002) $145-150$

[42] L. Brady, A.M. Brzozowski, Z.S. Derewenda, E. Dodson, G. Dodson, S. Tolley, J.P. Turkenburg, L. Christiansen, B. Huge-Jensen, L. Norskov, et al., A serine protease triad forms the catalytic centre of a triacylglycerol lipase, Nature 343 (1990) 767-770.

[43] N. Hulo, A. Bairoch, V. Bulliard, L. Cerutti, B.A. Cuche, E. de Castro, C. Lachaize, P.S. Langendijk-Genevaux, C.J. Sigrist, The 20 years of PROSITE, Nucleic Acids Res 36 (2008) D245-D249.

[44] C.J. Sigrist, L. Cerutti, N. Hulo, A. Gattiker, L. Falquet, M. Pagni, A. Bairoch, P. Bucher, PROSITE: a documented database using patterns and profiles as motif descriptors, Briefings Bioinf. 3 (2002) 265-274.

[45] R.D. Finn, J. Tate, J. Mistry, P.C. Coggill, S.J. Sammut, H.R. Hotz, G. Ceric, K. Forslund, S.R. Eddy, E.L. Sonnhammer, A. Bateman, The Pfam protein families database, Nucleic Acids Res. 36 (2008) D281-D288.

[46] P. Fojan, P.H. Jonson, M.T. Petersen, S.B. Petersen, What distinguishes an esterase from a lipase: a novel structural approach, Biochimie 82 (2000) 1033-1041.

[47] C. Schmidt-Dannert, Recombinant microbial lipases for biotechnological applications, Bioorg. Med. Chem. 7 (1999) 2123-2130.

[48] M. Nardini, B.W. Dijkstra, Alpha/beta hydrolase fold enzymes: the family keeps growing, Curr. Opin. Struct. Biol. 9 (1999) 732-737.

[49] P. van Baarlen, A. van Belkum, R.C. Summerbell, P.W. Crous, B.P.H.J. Thomma, Molecular mechanisms of pathogenicity: how do pathogenic microorganisms develop cross-kingdom host jumps? FEMS Microbiol. Rev. 31 (3) (2007) 239-277.

[50] A. Casadevall, L.A. Pirofski, Host-pathogen interactions: redefining the basic con cepts of virulence and pathogenicity, Infect. Immun. 67 (8) (1999) 3703-3713.

[51] A. Gacser, F. Stehr, C. Kroger, L. Kredics, W. Schafer, J.D. Nosanchuk, Lipase 8 affects the pathogenesis of Candida albicans, Infect. Immun. 75 (10) (2007) $4710-4718$.

[52] J. Feng, F. Wang, G. Liu, D. Greenshields, W. Shen, S. Kaminskyj, G.R. Hughes,
Y. Peng, G. Selvaraj, J. Zou, Y. Wei, Analysis of a Blumeria graminis-secreted lipase reveals the importance of host epicuticular wax components for fungal adhesion and development, Mol. Plant Microbe Interact. 22 (12) (2009) 1601-1610.

[53] S. Silva, M. Negri, M. Henriques, R. Oliveira, D.W. Williams, J. Azeredo, Adherence and biofilm formation of non-Candida albicans Candida species, Trends Microbiol. 19 (5) (2011) 241-247.

[54] A.S. Ibrahim, F. Mirbod, S.G. Filler, Y. Banno, G.T. Cole, Y. Kitajima, J.E. Edwards Jr., Y. Nozawa, M.A. Ghannoum, Evidence implicating phospholipase as a virulence factor of Candida albicans, Infect. Immun. 63 (5) (1995) 1993-1998.

[55] J.M. Manns, D.M. Mosser, H.R. Buckley, Production of a hemolytic factor by Candida-albicans, Infect. Immun. 62 (11) (1994) 5154-5156.

[56] M.A. Pfaller, R.N. Jones, S.A. Messer, M.B. Edmond, R.P. Wenzel, National surveillance of nosocomial blood stream infection due to species of Candida other than Candida albicans: frequency of occurrence and antifungal susceptibility in the SCOPE Program. SCOPE Participant Group. Surveillance and Control of Pathogens of Epidemiologic, Diagn. Microbiol. Infect. Dis. 30 (2) (1998) 121-129.

[57] M.M. Harriott, M.C. Noverr, Importance of Candida-bacterial polymicrobial biofilms in disease, Trends Microbiol. 19 (11) (2011) 557-563.

[58] M. Park, E. Do, W.H. Jung, Lipolytic enzymes involved in the virulence of human pathogenic fungi, MYCOBIOLOGY 41 (2) (2013) 67-72.

[59] S. Nicholls, D.M. MacCallum, F.A. Kaffarnik, L. Selway, S.C. Peck, A.J. Brown, Activation of the heat shock transcription factor Hsf1 is essential for the full virulence of the fungal pathogen Candida albicans, Fungal Genet. Biol. 48 (3) (2011) 297-305.

[60] J.E. Cutler, Putative virulence factors of Candida albicans, Annu. Rev. Microbiol. 45 (1991) 187-218.

[61] M. Monod, Z.M. Borg-von, Secreted aspartic proteases as virulence factors of Candida species, Biol. Chem. 383 (7-8) (2002) 1087-1093.

[62] M. Schaller, H.C. Korting, W. Schafer, J. Bastert, W.C. Chen, B. Hube, Secreted aspartic proteinase (Sap) activity contributes to tissue damage in a model of human oral candidosis, Mol. Microbiol. 34 (1) (1999) 169-180.

[63] B.N. Taylor, P. Staib, A. Binder, A. Biesemeier, M. Sehnal, M. Rollinghoff, J. Morschhauser, M. Schroppel, Profile of Candida albicans-secreted aspartic proteinase elicited during vaginal infection, Infect. Immun. 73 (3) (2005) 1828-1835.

[64] R. Gupta, A. Kumari, P. Syal, Y. Singh, Molecular and functional diversity of yeast and fungal lipases: their role in biotechnology and cellular physiology, Prog. Lipid Res. 57 (2015) 40-54.

[65] F. Dalle, B. Wachtler, C. L'Ollivier, G. Holland, N. Bannert, D. Wilson, C. Labruere, A. Bonnin, B. Hube, Cellular interactions of Candida albicans with human oral epithelial cells and enterocytes, Cell Microbiol. 12 (2) (2010) 248-271.

[66] J.R. Naglik, D.L. Moyes, B. Wachtler, B. Hube, Candida albicans interactions with epithelial cells and mucosal immunity, Microb. Infect. 13 (12-13) (2011) 963-976.

[67] F. Stehr, A. Felk, A. Gacser, M. Kretschmar, B. Mahnss, K. Neuber, B. Hube, W. Schafer, Expression analysis of the Candida albicans lipase gene family during experimental infections and in patient samples, FEMS Yeast Res. 4 (4-5) (2004) 401-408.

[68] T.A. Richards, D.M. Soanes, M.D. Jones, O. Vasieva, G. Leonard, K. Paszkiewicz, P.G. Foster, N. Hall, N.J. Talbot, Horizontal gene transfer facilitated the evolution of plant parasitic mechanisms in the oomycetes, Proc. Natl. Acad. Sci. U. S. A. 108 (37) (2011) 15258-15263

[69] J.M. Mancheno, M.A. Pernas, M.J. Martinez, B. Ochoa, M.L. Rua, J.A. Hermoso, Structural insights into the lipase/esterase behavior in the Candida rugosa lipases family: crystal structure of the lipase 2 isoenzyme at 1.97 angstrom resolution, J. Mol. Biol. 332 (5) (2003) 1059-1069.

[70] H. Zorn, H. Bouws, M. Takenberg, M. Nimtz, R. Getzlaff, D.E. Breithaupt, R.G. Berger, An extracellular carboxylesterase from the basidiomycete Pleurotus sapidus hydrolyses xanthophyll esters, J. Biol. Chem. 386 (2005) 435-440.

[71] P. Langcake, Uptake of sterols by phytophthora-infestans, their intracellular-distribution and metabolism, Trans. Br. Mycol. Soc. 64 (Feb) (1975) 55-65.

[72] W.D. Nes, A.E. Stafford, Evidence for metabolic and functional discrimination of sterols by Phytophthora cactorum, Proc. Natl. Acad. Sci. U. S. A. 80 (11) (1983) 3227-3231.

[73] C.A. Voigt, W. Schafer, S. Salomon, A secreted lipase of Fusarium graminearum is a virulence factor required for infection of cereals, Plant J. 42 (3) (2005) 364-375.

[74] G. Devescovi, J. Bigirimana, G. Degrassi, L. Cabrio, J.J. LiPuma, J. Kim, I. Hwang $\mathrm{V}$. Venturi, Involvement of a quorum-sensing-regulated lipase secreted by a clinica isolate of Burkholderia glumae in severe disease symptoms in rice, Appl. Environ. Microbiol. 73 (15) (2007) 4950-4958.

[75] A.B. Choupina, L. Estevinho, I.M. Martins, Scientifically advanced solutions for chestnut ink disease, Appl. Microbiol. Biotechnol. 98 (9) (2014) 3905-3909.

[76] S. Kamoun, Molecular genetics of pathogenic oomycetes, Eukaryot. Cell 2 (2) (2003) 191-199.

[77] J.E. Rookes, M.L. Wright, D.M. Cahill, Elucidation of defence responses and signalling pathways induced in Arabidopsis thaliana following challenge with Phytophthora cinnamomi, Physiol. Mol. Plant Pathol. 72 (4-6) (2008) 151-161.

[78] S. Kamoun, O. Furzer, J.D. Jones, H.S. Judelson, G.S. Ali, R.J. Dalio, S.G. Roy, L. Schena, A. Zambounis, F. Panabieres, D. Cahill, M. Ruocco, A. Figueiredo, X.R. Chen, J. Hulvey, R. Stam, K. Lamour, M. Gijzen, B.M. Tyler, N.J. Grunwald, M.S. Mukhtar, D.F. Tome, M. Tor, G. Van Den Ackerveken, J. McDowell, F. Daayf, W.E. Fry, H. Lindqvist-Kreuze, H.J. Meijer, B. Petre, J. Ristaino, K. Yoshida, P.R. Birch, F. Govers, The Top 10 oomycete pathogens in molecular plant pathology, Mol. Plant Pathol. 16 (4) (2015) 413-434.

[79] I.M. Martins, F. Martins, H. Belo, M. Vaz, M. Carvalho, A. Cravador, A. Choupina, Cloning, characterization and in vitro and in planta expression of a glucanase inhibitor protein (GIP) of Phytophthora cinnamomi, Mol. Biol. Rep. 41 (4) (2014) $2453-2462$. 
[80] S. Meirinho, M. Carvalho, A. Domínguez, A. Choupina, Isolation and characterization by asymmetric PCR of the ENDO1 gene for glucan endo-1,3-B-D-glucosidase in Phytophthora cinnamomi associated with the ink disease of Castanea sativa Mill, Braz Arch Biol 53 (3) (2010) 513-518.

[81] Y.J. Yu, S.C. Wu, H.H. Chan, Y.C. Chen, Z.Y. Chen, M.T. Yang, Overproduction of soluble recombinant transglutaminase from Streptomyces netropsis in Escherichia coli, Appl. Microbiol. Biotechnol. 81 (3) (2008) 523-532.

[82] P.N. Dodds, M. Rafiqi, P.H. Gan, A.R. Hardham, D.A. Jones, J.G. Ellis, Effectors of biotrophic fungi and oomycetes: pathogenicity factors and triggers of host resistance, New Phytol. 183 (4) (2009) 993-1000.

[83] G.J. Lawrence, P.N. Dodds, J.G. Ellis, Rust of flax and linseed caused by Melampsora lini, Mol. Plant Pathol. 8 (4) (2007) 349-364.

[84] A.M. Catanzariti, P.N. Dodds, G.J. Lawrence, M.A. Ayliffe, J.G. Ellis, Haustorially expressed secreted proteins from flax rust are highly enriched for avirulence elicitors, Plant Cell 18 (1) (2006) 243-256.

[85] D.J. Studholme, R.L. McDougal, C. Sambles, E. Hansen, G. Hardy, M. Grant R.J. Ganley, N.M. Williams, Genome sequences of six Phytophthora species associated with forests in New Zealand, Genom Data 7 (2016) 54-56.

[86] A. Reitmann, D.K. Berger, N. van den Berg, Putative pathogenicity genes of Phytophthora cinnamomi identified via RNA-Seq analysis of pre-infection structures, Eur. J. Plant Pathol. 147 (1) (2017) 211-228.

[87] M.A. Larkin, G. Blackshields, N.P. Brown, R. Chenna, P.A. McGettigan, H. McWilliam, et al., Clustal W and clustal X version 2.0, Bioinformatics 23 (2007) 2947-2948.

[88] L.A. Kelley, S. Mezulis, C.M. Yates, M.N. Wass, M.J. Sternberg, The Phyre2 web portal for protein modeling, prediction and analysis, Nat. Protoc. 10 (6) (2015)
$845-858$.

[89] A. Roussel, N. Miled, L. Berti-Dupuis, M. Riviere, S. Spinelli, P. Berna, V. Gruber, R. Verger, C. Cambillau, Crystal structure of the open form of dog gastric lipase in complex with a phosphonate inhibitor, J. Biol. Chem. 277 (3) (2002) 2266-2274.

[90] N. Cihangir, E. Sarikaya, Investigation of lipase production by a new isolate of Aspergillus sp, World J. Microbiol. Biotechnol. 20 (2004) 193-197.

[91] J.F. Burkert, F. Maugeri, M.I. Rodrigues, Optimization of extracellular lipase production by Geotrichum sp. using factorial design, Bioresour. Technol. 91 (2004) 77-84.

[92] P.O. Carvalho, P.R.B. Campos, M.D. Noffs, J.G. Oliveira, M.T. Schimizu, D.M. Silva, Application of microbial lipases to concentrate polyunsaturated fatty acids, Quim. Nova 26 (2003) 75-80.

[93] M. Elibol, D. Ozer, Response surface analysis of lipase production by freely suspended Rhizopus arrhizus Process, Biochemistry 38 (2002) 367-372.

[94] H.F. Castro, A.A. Mendes, J.C. Santos, C.L. Aguiar, Modification of oils and fats by biotransformation, Quim. Nova 27 (2004) 146-156.

[95] K. Toyama, T. Tauchi, N. Mase, H. Yoda, K. Takabe, Lipase-catalyzed kinetic resolution of thiotetronic acid derivatives bearing a chiral quaternary carbon: tota synthesis of (R)-thiolactomycin and its O-analogue, Tetrahedron Lett. 47 (2006) 7163-7166.

[96] M. Virto, C. F, M.A. Bustamante, L.J. Barron, M. Aramburu, M.S. Vicente, F.J. Pérez Elortondo, M. Albisiu, M. De Renobales, Lamb rennet paste in ovine cheese manufacture, Int. Dairy J. 13 (2003) 391-399.

[97] G.D.M. Freire, F.L. Castilho, Lipases em biocatálise, in: E.P.S. Bon, M.A. Ferrara, M.L. Corvo (Eds.), Enzimas em biotecnologia: Produção, Aplicação e Mercado, Interciência, Rio de Janeiro, 2008, p. 506. 